\title{
The Complex Political Economy of Natural Capitalism: The Case of Whole Foods, Stonyfield Farms, and Walmart
}

\section{Rubén Ramírez Sánchez, University of Puerto Rico, Puerto Rico}

\begin{abstract}
This paper examines the ideas presented in the proposal of "natural capitalism" by paying attention to three cases that exemplify the conflation of business and market ideals - such as profit and consumption - with environmental change: Whole Foods, Stonyfield Farm, and Walmart. While proponents of natural capitalism offer a mostly optimistic solution to our current environmental crisis that is synthesized by the power of markets, technology, and consumption to halt the perils of environmental degradation, a deeper criticism of these strategies reveals the inherent contradictions of the conflation of environment and capital and its seeming impossibility. While necessary, these critiques mostly fail to examine the complex discursive and political repercussions of actual manifestations of natural capitalism and realistic prescriptions for action. The main objective of this article, then, is to examine these two opposing viewpoints through a theory of articulation as a means for working toward ontology of environmental change.
\end{abstract}




\section{Parallel Capitalisms: Evaluating Natural Capitalism through a Theory of Articulation}

Critical and cultural scholarship has widely addressed the social, political, and economic consequences of the capitalist system of production, especially in its shift to what are often called neo-liberal and globalization economies. Political economy, for instance, has addressed the negative impact of corporate logic, especially in terms of the accumulation of corporate power and its imminent deterioration of true democracy and justice. Cultural studies, likewise, has been keen in the construction of theories and descriptions that foreground the ways through which power is consolidated by means of the sedimentation of belief systems, values, and norms that serve to reproduce capitalism as an overarching logic that governs most, if not all, aspects of human activity in industrial and post-industrial societies.

There is a sense that our current times encompass a crisis in capitalism that might signal the collapse of that system as we know it or, worse, the very collapse of human activity and existence. Capitalism is perceived to be at its frayed ends, and this perception is fueled by an expanding global economic crisis, growing and deteriorating political crises and wars, and the global threat of environmental collapse. Social movements against the threats posed by capitalism have been catalogued and studied. The change that these movements propose and for which they advocate corresponds to a clear message that the world's current political, economic, social, and environmental situation must somehow change toward a more productive direction. If, indeed, humanity is heading, in historical terms, toward a systems crisis of dire consequences for not only those who have traditionally held the cost of capitalism but those who have steered the direction of capitalism itself, it becomes increasingly necessary to re-examine historically fixed notions of resistance, opposition and social change and to analyze the very mechanisms through which changes can be accomplished. That is, an ontology of social transformations and, in this case, progressive environmental transformations.

This paper aims to explore an ontological approach to environmental change in capitalism in order to raise critical questions that may stimulate debate about relatively stable conceptions of resistance and opposition and, more importantly, to propose a direction for specifically analyzing the nature and scope of transformational practices whose objective is to prompt environmentally conscious actions. Specifically, I will analyze "natural capitalism"—and its proposition that environmental change can be best achieved by business and markets through 
the conflation of environment and capital —in light of three recent cases that embody its ideals: Whole Foods Market, Stoneyfield Farm, and Walmart. Contextualizing the analysis within the theoretical framework of articulation, I frame these cases within current critiques of natural and green capitalism in order to bring forth the inherent tensions of balancing the need for environmental action against actual capital-driven measures and the practical limitations of current critique of the natural capitalism phenomenon. I conclude with a discussion of the contribution of a theory of articulation for shaping ontology of progressive environmental action.

\section{The Environment in Crisis and the Debated Inevitability of Change}

Social, political, and cultural debates and actions about the negative effects of capitalism in the environment serve as the basis for an ontology of change in capitalism for several reasons. First, the environment issue has generated a forceful global and political debate prescribing urgent steps aimed at transforming policies and practices that generate, promote, and fixate environmental exploitation and degradation. For instance, the Copenhagen Climate Summit in 2009 exemplifies the political impact of the environment debate, with countries such as China, Great Britain, and the United States officially recognizing the perils of global warming and the scientific evidence for keeping temperatures from rising more than 2 Celsius.

Second, the environment issue has sparked speculation about the end of capitalism, at least as it is known today. Ideas about the end of capitalism are particularly important, since they present theoretical and practical dilemmas about the plausibility of a collapse of capitalism and, most importantly, about alternative systems that might take its place. Certainly, such debates connect well with Marxist debates about socialism and communism and fears about totalitarianism or the appropriateness of new, untested systems.

Finally, environmental issues have tended to escape critical/cultural debates. As Potter (2008) asserts, there is a real need for studies of culture, especially cultural studies, to incorporate environmental critique as an important category analysis. In addition, as a cultural phenomenon, environmental debates and actions serve as a current and significant site for analyzing issues of politics, agency, perception, media representation, and resistance. 
In terms of this paper, the reasons listed above are compelling not only because of the currency and significance of the environment debates, but because various manifestations of the environment issue also point to a juncture that might tell us something deeper about social processes generally and how social change might take place specifically. More precisely, I see these debates as important cases that inform a theory of hegemonic processes and one important ramification of it: the articulation and re-articulation of socio-cultural space.

\section{On Articulating and Re-Articulating the Social}

One important characteristic of articulation is that it is a multidimensional process. Primarily, articulation applies to the complexity of social practices. That is, people create articulations for developing and negotiating their cultural identifications and ideological positions through communication and praxis. In this respect, articulation is deeply rooted in the discursive realm of cultural experience.

Stuart Hall (1982, 1991, 1993, 1996/2003) conceives the process of articulation in terms of the politics of power relations in the representational world. Contrary to a crude Marxist conception of economic and class determinations, Hall argues for a conception of social structures as not being guaranteed by structural preconditions. Economic determinism implies that social structures are the product of rigid relationships that situate human experience into predetermined social, political, and economic positions that are impossible to transcend. Social categories or identifications such as class, gender, and ethnicity cannot be structured in multiple ways and are reduced to their place within the system of production. A theory of articulation aims to describe the complex ways through which social formations emerge, are secured, and challenged.

Laclau (1977), in one of the first theoretically grounded accounts of articulation processes, asserts that ideological positions are not determined by fixed identities but rather by what can be described as social, political, and cultural identifications. In his historical examination of how populist movements come to be represented as "populist," he proposes that the ideological consistency of the idea of "populist" depends not on an a priori populist identity but on the way people identify with and connect values and ideals. For instance, Laclau observes how an ideal such as "democracy" can be linked to a worker's ideology but also to a fascist ideology. This is possible because social groups are able to articulate their own social 
positions to different social meanings. Discursive connections are then a matter of political significance, since a class may become dominant not necessarily by imposing a "uniform conception of the world on the rest of society, [but by articulating] different visions of the world in such a way that their potential antagonism is neutralized" (Laclau, 1977, p. 161).

The notion of articulation is deeply connected to Gramsci's idea of hegemony, which could be said to serve as the context through which articulations take place. The process of hegemony implies that "the dominance of certain formations [is] secured, not by ideological compulsion, but by cultural leadership" (Hall, 1982, p. 85). This is to say that the ideologies of a dominant bloc are not prevalent in and by themselves; to the contrary, they can only maintain their dominant position by means of gaining the support of people through the creation of consent, by negotiating the cultural arena through the articulation of key social values, representations, and means.

Articulation is the means through which a dominant bloc fixes dominant ideological significations in the social realm, but it is not exclusive to a dominant bloc nor are these significations absolute. As Laclau and Mouffe (1987) assert, "the terrain of hegemonic practices is constituted by the fundamental ambiguity of the social, the impossibility of fixating the ultimate meaning of any struggle" (p. 281, translation mine). Thus, articulations have to be "positively sustained by specific processes" (Hall, 1991, p. 112) in order to maintain their representational status. The fact that they have to be "sustained" opens the possibility for "re-articulations."

Therefore, even if articulations do operate in the discursive, they still have material consequences. We can talk about cultural terrains being contested, negotiated, and controlled. This struggle is what Hall (1982) calls the "politics of signification" (p. 70), and it is by means of this struggle that dominant meanings are articulated and re-articulated. Indeed, Hall (1993) talks about "dominant" and not "determined" because "it is always possible to order, classify, assign and decode an event within more than one "mapping'" (p. 98). However, Hall (1996/2003b) recognizes that some articulations have become "tendential forces" "that are difficult to break because [their] ideological terrain (...) has been so powerfully structured (...) by its previous history (p. 43). 
Slack (1996/2003) has expanded the concept of articulation as theory, method, and intervention. If we look at theory through the concept of articulation-as points of conjuncture within the ideological, representational, and political dimensions of experiencethen theories are not fixed or essential explanatory constructs that bear an a priori "fit" with the phenomena they aim to explain, but rather incomplete structures that we use "to move understanding 'a little further on down the road"' (Slack, 1996/2003, p. 113). Articulation as theory and method is central to the construction of knowledge about culture itself just as it is central to the construction of culture in everyday life. It is in this sense that articulation is fundamental to the study of culture since, as Slack rightly asserts, "this is what a cultural study does: map the context - not in the sense of situating a phenomenon in a context, but in mapping a context, mapping the very identity that brings the context into focus" (p. 125). Another important characteristic of articulation is that it is also a tool for intervention. If articulation is the mechanism through which different social formations can be articulated with different ideologies into particular social formations, then it is possible to think about strategic articulations and re-articulations. In this respect, the social terrain is never absolute and is always negotiated and contested.

As Slack, interpreting Hall, put it, "if each component or moment in the process of communication is itself an articulation, a relatively autonomous moment, then 'no one moment can fully guarantee the next moment with which it is articulated"' (p. 124). Thus, articulation as intervention implies that there is the possibility to tactically develop articulations that can advance the struggle to interrupt hegemonic processes. The role of theory, in this respect, is to facilitate the advancement of new and effective forms of articulation that could validate and advance different forms of resistance as praxis. Articulation as theory and method is inherently political: "Determining when, where and how [cultural] circuits might be re-articulated is the aim of a cultural theorist's theoreticallyinformed political practice" (Slack, 1996/2003, p. 124). One objective of this paper is, then, to offer such as theory of articulation as a framework against which we can analyze complex phenomena that are exerting pressure on the broader capitalist system in order to transform its environmental direction. 


\section{Articulating Capital to the Environmental Cause}

It has been widely discussed and broadly accepted that global warming caused by industrial and post-industrial modes of production is putting the environment under great pressure and, consequently, toward a direction of collapse. Because the practices that sustain capitalism have been widely identified as the propellers of such a situation, possible solutions to this problem have revolved around changing those aspects of the capitalist system that have been identified to be directly responsible for environmental degradation: A materials economy, linear cycles of production and consumption, depletion of natural resources.

Of such proposals, so called "natural" or "green" capitalism, and some of its implications, are of interest. This interest arises from their attempt to solve the environmental problem through the very logic that has prompted the conditions through which environmental degradation has been accelerated, namely capitalism's ever escalating quest for profit. In this respect, natural or green capitalism aim at deterring, and eventually stopping, rising $\mathrm{CO} 2$ levels, natural resource exploitation, and pollution of ecosystems while maintaining current paradigms of profit, growth, and expansion. Further, consumption fits within the framework of natural capitalism because, on the one hand, it would serve as a catalyst for a transition toward such a system and, on the other hand, it would remain an indispensable aspect of capitalism's sustenance. To many, nonetheless, such an idea is incongruent, contradictory, or impossible.

\section{Natural Capitalism}

The idea of natural capitalism was formally proposed in 1999 by Paul Hawken, Amory Lovins, and L. Hunter Lovins through the publication of Natural Capitalism: Creating the Next Industrial Revolution. One main tenet of the book is that capitalism has come to a crossroads. The capitalist system, they argue, has significantly depleted the resources, or natural capital, that has supported it in the first place without taking care of replenishing the resources it has exploited for sustaining massive cycles of production and consumption. Through such a linear system that extracts but does not give back to the planet, capitalism has become dangerously unsustainable, and has already put natural systems through a path of imminent failure. They exemplify the conundrum:

Today, our continuing progress is restricted not by the number of fishing boats but by the decreasing numbers of fish; not by the power of pumps but by the depletion of 
aquifers; not by the number of chainsaws but by the disappearance of primary forests. (Hawken, Lovins, Hunter Lovins, 1999, p. 3)

Natural capitalism, however, offers an alternative to this bleak scenario that would not only deter and eventually revert environmental collapse but that would also create a new era of capitalism characterized by the same governing principles on which it is founded: Commerce, growth, profit. It is even suggested in the book that natural capitalism presents itself as an inevitable stadium of capitalist development, prompted by the threat of nature's collapse which, in turn, represents a dramatic halt to capitalism itself, since it would not be able to be materially sustained. More importantly, it is also implicit that the end of capitalism would ultimately be decimated by the collapse of human existence in itself.

Thus, natural capitalism is not a "new" form of capitalism, but a consequential evolution of it. It is fostered by principles that diverge from "conventional" capitalism, but not by its industrial overarching logic. In this respect, such kind of capitalism would be supported by a view of natural resources and the environment not as mere prime materials, but as the most important factors sustaining an economy, and their availability and sustainability would be considered crucial factors. Another factor supporting such a system would be a market guided by the protection of all forms of capital, including human, manufactured, financial, and natural. This, in turn, would require truly democratic systems through which social inequalities are addressed and that put people's needs above other considerations, such as profits. Amory Lovins, who has been an environmental consultant for high profile companies such as Walmart, summarizes the idea behind natural capitalism:

If capitalism is a productive use of and reinvestment in capital, we can't deal only with financial and physical capital-money and goods. We also need to productively use and reinvest in two more valuable kinds of capital-people and nature. If you play with a full deck, using all four kinds of capital, then you make more money, do more good, and have more fun. (Lovins in Hopkins, 2009, p. 36).

Specifically, they provide a model founded on four pillars: Radical resource productivity, biomimicry, a service and flow economy, and investment in natural capital. More importantly, the basis of all these changes, which stems from technological innovations that 
are currently available, can already become to be instituted and implemented. Further, they assert, these changes would amount to the next industrial revolution.

\section{Three Examples of "Natural" Capitalism}

While the idea of natural capitalism is founded on very specific principles and tenets, it can be said that the possible evolution toward such a system is taking the form of the "green" phenomenon: Green bags at the grocery store, biodegradable detergents by multinational, corporate brands such as Clorox, the increasing availability and accessibility of hybrid and electric cars, among many other examples from everyday life.

However, more profound changes in the market have been taking place, specifically the growth of companies that have been able to make great amounts of capital while committing to a broad natural capitalism view. One example is Whole Foods Market, a natural and specialty foods market that has grown in such a way as to expand through numerous US cities. The company, which is based in Austin, Texas, started in the early 80s. Currently, it operates about 207 stores and holds sales of about eight billion dollars a year (Paumgarten, 2010).

The company went public in 1991, after which it began to quickly gain terrain in specific markets such as seafood, cheese, and its own private-label products. It is an undeniable fact that Whole Foods is currently a giant corporate player. For instance, in 2007, the company announced it acquisition of rival Wild Oats, at a value of approximately $\$ 565$ million (Austin Business Journal, 2007), which prompted the Federal Trade Commission to investigate and initially oppose the merger, on claims that it would monopolize the premium natural and organic supermarket sector (Federal Trade Commission, 2009).

John Mackey, the co-founder and CEO of Whole Foods, confirms the corporate status of the company and offers insight into its shareholders' monetary benefits. For example, he possesses around thirty million dollars in stock and has sold millions more over the years (Paumgarten, 2010). He also embraces some of the market economy's orthodox views, such as fervent support of laisser-faire policies. In august, 2009, he published an opinion editorial titled "The Whole Foods Alternative to ObamaCare: Eight things we can do to improve health care without adding to the deficit," in which he claims, among other things, that health care companies should be freer from government restraints, such as laws preventing companies 
from competing between states and mandates that regulate obligatory coverage of specific conditions and procedures (Mackey, 2009).

Still, within this corporate context, Whole Foods does embrace practices that are more closely related to natural rather than conventional capitalism. For instance, the company follows a manifesto, a "Declaration of Interdependence," that defines its core values:

Our motto - Whole Foods, Whole People, Whole Planet - emphasizes that our vision reaches far beyond just being a food retailer. Our success in fulfilling our vision is measured by customer satisfaction, Team Member excellence and happiness, return on capital investment, improvement in the state of the environment, and local and larger community support. (Whole Foods Market company website)

These values are supported by efforts to incorporate into their selling, production, and distribution practices the banning of genetically modified foods, the eradication of plastics bags, and the increasing use of renewable sources of energy.

Another example is Stonyfield Farm, an organic yogurt company that has become the leading brand of organic yogurt and the number three brand of yogurt in the United States. As of 2008, the company has produced revenues of 300 million dollars. Stonyfield Farm is also committed to values embraced by a natural form of capitalism. For instance, it is preoccupied with its operational and production processes, so it relies on renewable sources of energy for running its factories. It has an "energy team" whose main purpose is to make production more efficient and sustainable through the use of renewable energy sources, such as eolic and solar, structural improvements, and the compilation of complex carbon footprint data for organizing transportation methods and means. It also depends on a vast pool of organic dairy farms that produce milk from cows that have not been treated with hormones, are grass fed, and are treated humanely. Additionally, the company donates 10 percent of its profits to environmental projects and organizations, purporting to have donated over 10 million over the last two decades (Stonyfield Farm company website).

As Whole Foods, Stonyfield is also a public corporation that is very interested in conflating capitalist ideals, such as increasing growth and profit, with sustainability, environmental reparation, and even increased value and benefits for communities at large. This logic is 
exemplified by Gary Hirshberg, an environmental activist turned capitalist, or "ecoentrepreneur," who vocally subscribes to a form of capitalism that can be sustainable yet incredibly profitable. Hirshberg, as he recalls in the documentary Food Inc., realized at some point in the seventies that environmental change could not come from preaching at the converts. "I realized we need not to be David against Goliath, we need to be Goliath," he states (in Kenner, 2009). This is most apparent in the rhetoric of his recent book, about the rise of Stonyfield and its success, in which he states the following:

Business is the most powerful force on Earth. Unlike governments, which are usually bound up by politics and conventions, business can lead. Unlike churches, community groups, and nonprofits, business has money to back up its ideas. It can act quickly, get rules changed, and overcome entrenched interests. In one of those twists that make life so interesting, the same boundless thirst for profit that got the planet into trouble can get us out of it. (Hirshberg, 2008, p. 4)

One idea that he advocates is that consumers can exert pressure on capitalism in order to accomplish changes in it. For example, in the company's website they state that "The grocery checkout is a voting booth. You can vote for organic or not, pesticides or not, climatefriendly practices or not." He supports this in his book as well, stating that it is "exciting to think of price-conscious shoppers the world over voting with their pocket books to save the Earth" (Hirshberg, 2008, p. 114).

This last idea that of consumers as propellers of change in capitalism, connects to a third example, Walmart's recent efforts to "green" itself. In 2005, Walmart announced that it would begin serious steps toward a "sweeping sustainability strategy." In 2006, the company began requiring that its fish, which make up a third of its seafood sales, be produced under the Marine Stewardship Council's standard for sustainable and well-managed fisheries (Gogoi, 2006). In 2008, Walmart announced that it would not continue using milk produced with recombinant bovine somatotropin (rBST) hormones in its Great Value milk. As of today, Walmart has continued a sustained effort of energy efficiency. As the company purported in their website on April 22, 2009:

Today Walmart Stores, Inc., as part of its commitment to accelerate and broaden its sustainability efforts, announced it is expanding its solar power program in California. The company plans to add solar panels on 10 to 20 additional Walmart facilities 
within the next 18 months. This commitment is in addition to the 18 solar arrays currently installed at Walmart facilities in California. When combined, Walmart's total solar installations are expected to: Generate up to 32 million kilowatt hours $(\mathrm{kWh})$ of renewable energy per year-the equivalent of powering more than 2,600 homes; Avoid producing more than 22,500 metric tons of carbon dioxide emissions per year - the equivalent of taking more than 4,000 cars off the road; Provide 20 to 30 percent of each location's total electric energy needs. (Walmart company website) But, as proclaimed by the tenets of natural capitalism, and as exemplified by Whole

Foods and Stonyfield, the drive for these changes rests more on the very capitalist logic than on a broader environmental concern. This is exemplified by an article in the Stanford Social Innovation Review:

Elm and Andrew Ruben, Walmart's vice president of corporate strategy and business sustainability, directed Walmart's network leaders to "derive economic benefits from improved environmental and social outcomes," says Elm. "It's not philanthropy," he adds. By the end of the sustainability strategy's first year, the network teams had generated savings that were roughly equal to the profits generated by several Walmart Supercenters, Ruben and Elm report. (Plambeck \& Denend, 2008)

What should be noticed about these companies is that they utilize a capitalist framework to exploit a specific market and, more importantly, they put market forces, such as profit and consumers, to be at the forefront of much needed changes in the capitalist paradigm. Just like natural capitalisms' harbinger, the answer to the destruction propelled by capitalism can be fixed by capital, only with a few transformations. Whole Foods' John Mackey summarizes as follows:

On one side of the wall is this belief that not-for-profits and government exist for public service, and that they're fundamentally altruistic, that they have a deeper purpose, and they're doing well in the world, and they have pure motives. On the other side of the wall are corporations. And they're just selfish and greedy. They have no purpose other than to make money. They're a bunch of psychopaths. And I'd like to tear that wall down. Human beings are obviously self-interested. We do look after ourselves, but we're capable of love, empathy, and compassion and I don't see 
that business is any different. We're trying to do good. And we're trying to make money. The more money we make the more good we can do.” (Paumgarten, 2010)

Gary Hirschberg supports this insight:

When I run into my old environmental friends, they are initially horrified by the kinds of companies I'm keeping these days. When I then go on to explain what the impact of one purchase of Walmart is in terms of not pounds but tons of herbicide, tons of herbicide, tons of fertilizer, we get away from emotion and get down to the facts. (in Kenner, 2009)

Finally, Tony Airoso, a dairy purchaser for Walmart, explains one of the company's main drive toward change:

It's a pretty easy decision, trying to support organic, or whatever it may be, based on what the customer wants. We see that and react to it. If it's clear the customer wants it, it's really easy to get behind it and to push forward and try to make it happen. (in Kenner, 2009)

\section{Green Capitalism under Suspicion}

The incongruence of the concepts that make up something like "natural" or "green" capitalism have brought attention to, at best, a perceived suspicion of the capitalist enterprises described here and, at worse, a total lack of credibility in terms of any real change that might occur from their practices. The concerns that have been raised are serious and need special consideration. Nonetheless, one objective of the work presented here is to examine these important shifts in the capitalist logic and scrutinize them within a theoretical framework that might help us understand how, in particular, meaningful environmental changes can take place and, in general, how change is effected in society at large. Thus, I propose that a theory of articulations might help in the elaboration of tools to understand these changes, on the one hand, and to develop strategies for directing specific changes, on the other.

Through existing critiques of natural or green capitalism, we can see how discursive articulations do take place within debates on the environment, but we can also witness how the need for articulations - actual connections of people sustained by temporary ideological associations - become imbued in the language of critique. Kendall (2008), for example, criticizes natural capitalism, as professed by Hawken, Lovins, and Lovins, by foregrounding 
how the capitalist ideals that sustain a natural capitalist perspective still serve to perpetuate the social problems they aim to avoid. For example, by examining the rhetoric of their discourse through persona criticism, he argues that

Natural Capitalism constructs a second persona determinable in its pragmatism, instrumental and technical response to social problems, and acceptance of private accumulation of capital. Further, citizens and non-profit collectives in civil society constitute a silenced third persona: they are granted moral standing in natural capitalism, but are implicitly denigrated as capable decision-makers when measured against the constituents of the second persona. (Kendall, 2008, p. 71)

Here, it is clear that the conflation of "natural" and "capitalism," as a discursive articulation, serves to construct a hegemonic discourse that would legitimate this kind of capitalism by building consensus through some compromises but not through radical democracy. Thus, "consensus - not resistance, opposition, negotiation, or other conditions of agitation-is the wellspring of business innovation in the face of ecological crisis" (Kendall, 2008, p. 72).

Additionally, such a conflation enables capital to accommodate production to environmental demands, not only through the development of efficient technologies but also through the configuration and iteration of discourses that work to positively establish an effective articulation between environmental change and the accumulation of capital. In terms of the three cases presented here, the "citizen-consumer" dichotomy that supports a green capitalist logic (i.e., the cash register as a voting booth) becomes a discursive mantra that empowers the articulation while effacing the contradictions of environment and capital. While research from a market perspective on consumers' influence on corporate decisions about the environment and environmental policy offer insights into a consolidated belief and interest on citizen-consumers and their influence (Connoly \&Prothero, 2003; Collins, Steg, \& Koning, 2007), there is also a belief that the purported power of the citizen-consumers is actually obscured by the contradictions it espouses (Varman \& Manohar Vikas, 2007; Johnston, 2008). Johnston's persuasive examination of Whole Foods Market's construction of its citizen-consumer brings forth the problem that such a discourse dilutes the urgency of environmental action and idealizes the true power of consumer behavior. Contradictions such as what he calls "conservation through consumption," "a view of nature that maximizes commodity choice, while minimizing the citizen's ecological responsibilities to restrain 
consumption, reduce needs, and simply buy less" (p. 259) exemplify the incompatibility of environment and capital.

The incongruities of discursive articulations of environment and capital are also exemplified by the increasing role of celebrities and public personalities in the portrayal of green capitalism. Related to the effect of citizen-consumers, personalities with representational power help to promote ideas about an environmentally-conscious capitalism that may be at odds with actual progressions toward meaningful environmental change. Brockington (2008) demonstrates suspicion of the rise of celebrity environmentalists by foregrounding the intrinsic nature of their career practice:

There is a powerful logic behind the growth of celebrity conservationists. Being a celebrity of any sort, conservation or otherwise, is a business. It will require selfpromotion: appearing in public often and preferably being paid to so. It requires selling commodities, either other people's (such as newspapers, films and books) or one's own. One of the main commodities which celebrity conservationists can offer is closeness to nature, and experience of the same. (Brockington, 2008, p. 561)

Implicit in this statement is the glamorization of environmental causes and, most importantly, the commodification of environmental discourse in the service of a logic intrinsic to latecapitalism, that of the representation as an index of reality. Likewise, talking about Richard Branson's public (that is, representational) incursions in the media about his environmental commitment, Prudham (2009) synthesizes the nature and effect of celebrity environmental advocacy: "For green capitalism to 'work', environmentalism and capitalism must be understood not as antagonisms but, rather, as a combatable fusion embodied in technoeconomic trajectories, as well as in the figure of the bourgeois subject himself or herself" (p. 1,605).

Critical, yet cautions critics such as Wallis (2010) address the complexities of green capitalism while hinting at the opportunity that some of its platforms may offer. In his critique, he rightfully acknowledges the problems with technologies that would serve as platform for such a kind of capitalism, understanding that mechanisms of renewable energy, for instance, also "have their costs - in terms of installation, collection, maintenance, and transmission" (p. 36). What is implicit in the articulation of discourses as they pertain to 
natural capitalism is that talk about what counts as a solution can never fully grasp the totality of discourses and, more importantly, the parameters of debate can be delimited by power. This view connects with Davison's (2008) problematization of sustainability, which asserts that terms encompassing nature "makes it prey to co-optation by entrenched ideological and economic interests of dominant discourses and empowered institutions" (p. 191).

The seeming problem of green or natural capitalism is that it is an impossible relation. As two activists have put it

Just as the antagonism between labour and capital cannot be solved within a capitalist framework-it is, after all, the very constituent feature of the capitalist mode of production - the antagonism between capital and life in relatively stable eco-social systems cannot be solved, because there is a necessary contradiction between the infinite accumulation of capital, and life on a finite planet. (Mueller \& Passadakis, 2009, p. 58)

Wallis too understands green capitalism as an oxymoron, yet recognizes that it is still a policy objective. In view of an ecological emergency, he acknowledges that "immediate proecology steps are needed, irrespective of their sponsorship" (p. 33). He understands that a capitalist approach to changes in environmental policy would not produce long-lasting, democratic, truly transformational results. He can only see this if changes came about through people, a coalition of the stakeholders of environmental degradation. However, he recognizes that "the ecological movement has not yet been able to mount a socially persuasive agenda for reducing energy consumption on a large scale" (p. 37).

\section{Conclusion: Toward A Realistic Ontology of Environmental Change?}

I have presented, on the one hand, the logic behind natural capitalism (as proclaimed by some key supporters) and analyzed three cases exemplifying its real manifestation in society. On the other hand, I have also presented the position of critics who argue that a marriage between capital and environment is impossibility or, worse, an integral aspect for the development of our current capitalist stage; in which exploitation and accumulation still govern its modus operandi. These criticisms, in consequence, point to the failure of such measures and would perhaps persuade the public, intellectuals, and policy makers to abandon environmental actions closely associated with capitalism. Just as an articulation of nature and capital is 
currently underway, the inherent tensions of conflating environment and the capitalist logic prompt justifiable and, mostly, relevant criticism of this discursive marriage.

A theory of articulation, however, may offer different directions for thinking about this conundrum. First, a theory of articulations puts forth the idea that cultural processes and changes in the social sphere are not clearly delimited events whose mutual influence and products can be segmented and removed, but rather a complex of determinations, in particular historical contexts, that are produced in multiple and not necessarily predetermined ways, and whose future outcomes may or may not follow an intended prescription. Second, it foregrounds that the connection that can be made between an ideology and a social group is only limited by the ability of positively maintaining such a connection, which is not necessarily governed by its usefulness or practicality but by multiple determinations that may, or may not foment, institute, and fix a particular connection in a particular context. That is to say, the articulation between capital and environment, whether it works, is productive, or progressive, is still a very real articulation that has been positively and successfully maintained and expanded by corporations and markets.

One of the main objectives of this article is to open-up truly critical debate about environmental action and, most importantly, its forceful and very real articulation to the very logic of capitalism. In this respect, we need not first ask whether these articulations must be discarded or eschewed or examine the conditions that make them possible in the first place in order to direct their flow in more meaningful or productive directions. The critical work examined here is part of this effort - as it aims to decode critical problems-yet it mostly fails to realize and grapple with the future development of these problems or real conditions of intervention.

How, we should ask, should these coalitions between environment and capital take place in order to produce meaningful change? There is not a single, overarching answer to this question. To say, like Kendall (2008), that "natural capitalism does not overcome the contradictions and injustices of the history of capitalism, but is an iteration of it" (p. 74) does not really factor in important variables that, in historical terms, do signal a shift in the capitalist paradigm. Can we really say that the practices of Whole Foods, Stonyfield, or Walmart have not amounted to any impact toward a paradigm change at the structural, ideological, and cultural levels? What kind of impact has occurred and can occur? 
To understand an articulation between capital and environment from the lens proposed here entails further complexity in the critique of the articulation but also a realization of the potential of an articulation to be re-articulated toward more productive directions. Any such shift, undoubtedly, is not utopian. However, what I believe a theory of articulations proposes is a way for understanding these shifts as momentum for other articulations. Not only that, if a theory of articulation can lead to a map of intervention, of strategies for building other articulations, then we need to pay closer, more objective attention to the changes described here, not only to criticize their weaknesses and injustices, but to identify conjunctures, nodes for deploying more meaningful actions and for discerning lines of flight. 


\section{References}

Austin Business Journal. (2007, February 22). Whole Foods to acquire Wild Oats. Retrieved on June 28, 2011, from

http://austin.bizjournals.com/austin/stories/2007/02/19/daily28.html?surround=lfn

Brockington, D. (2008). Powerful environmentalism: conservation, celebrity and capitalism. Media, Culture \& Society, 30(4), pp. 412-417.

Collins, C., Steg, L. \& Koning, M. (2007). Customers' values, beliefs on sustainable corporate performance, and buying behavior. Psychology \& Marketing, 24(6), pp. $555-577$.

Connolly, J. \& Prothero, A. (2003) Sustainable Consumption: Consumption, consumers and the Commodity Discourse. Consumption, Markets and Culture, 6(4), pp. 275-291.

Davison, A. (2008). Contesting sustainability in theory-practice: In praise of ambivalence. Continuum: Journal of Media and Cultural Studies, 22(2), pp. 191-199.

Gogoi, P. (2006, March 29). Wal-Mart's organic offensive. Business Week. Retrieved on June 28, 2011, from http://www.businessweek.com/bwdaily/dnflash/mar2006/nf20060329_6971.htm

Hall, S. (1982). The rediscovery of "ideology": Return of the repressed in media studies. In M. Gurevitch, T. Bennett, J. Curran, \& J. Woollacott (Eds.), Culture, media and society (pp. 88-113). New York: Routledge.

Hall, S. (1991). Signification, representation, ideology: Althusser and the post-structuralist debates. In R. K. Avery, \& D. Eason (Eds.), Critical perspectives on media and society (pp. 88-113). New York: The Guilford Press.

Hall, S. (1993). Encoding, decoding. In S. During (Ed.), The cultural studies reader (pp. 90103). New York: Routledge.

Hall, S. (1996/2003). On postmodernism an articulation: An interview with Stuart Hall (L. Grossberg, Ed.). In D. Morley \& K-H. Chen (Eds.), Stuart Hall: Critical dialogues in cultural studies (pp. 131-150). New York: Routledge.

Hawken, P., Lovins, A. B., \& Hunter Lovins, L. (1999). Natural capitalism: Creating the next industrial revolution. Boston: Little Brown and Co.

Hirshberg, G. (2008). Stirring it up: How to make money and save the world. New York: Hyperion.

Hopkins, M. S. (2009). What executives don't get about sustainability (and further notes on the profit motive). MIT Sloan Management Review, 51(1), pp. 34-40. 
Johnston, J. The citizen-consumer hybrid: ideological tensions and the case of Whole Foods Market. Theory and Society, 37(3), pp. 229-270.

Kendall, B. E. (2008). Personae and natural capitalism: Negotiating politics and constituencies in a rhetoric of sustainability. Environmental Communication, 2(1), pp. 59-77.

Kenner, R. (Director). (2009). Food, inc. [Motion picture]. Magnolia Home Entertainment. Kozinets, R. V. \& Handelman, J. M. (2004). Adversaries of Consumption: Consumer, Movements, Activism and Ideology. Journal of Consumer Research, 31(3), pp. 691704.

Laclau, E. \& Mouffe, C. (1987). Hegemonía y estrategia socialista: Hacia una radicalización de la democracia. Madrid: Siglo Veintiuno.

Laclau, E. (1977). Politics and ideology in Marxist theory: Capitalism, fascism, populism. London: NLB.

Mackey, J. (2009, August 11). The Whole Foods Alternative to ObamaCare: Eight things we can do to improve health care without adding to the deficit. The Wall Street Journal. Retrieved on June 28, 2011, from http://online.wsj.com/article/SB10001424052970204251404574342170072865070.ht $\mathrm{ml}$

Mueller, T. \& Passadakis, A. (2009). Green capitalism and the climate: It's economic growth, stupid! Critical Currents, 6, pp. 54-61.

Paumgarten, N. (2010, January 4). Food fighter: Does Whole Foods' C.E.O. know what's best for you? The New Yorker.

Plambeck, E. L., \& Denend, L. (2008). The greening of Wal-Mart. Stanford Social Innovation Review, spring, pp. 53-59.

Potter, E. (2008). A sustainable practice: Rethinking nature in cultural research. Continuum: Journal of Media and Cultural Studies, 22(2), pp. 171-178.

Prudham, S. (2009) Pimping climate change: Richard Branson, global warming, and the performance of green capitalism. Environment and Planning, 41, pp. 1594-1613.

Slack, J. D. (1996/2003). The theory and method of articulation in cultural studies. In D. Morley \& K-H. Chen (Eds.), Stuart Hall: Critical dialogues in cultural studies (pp. 112-127). London and New York: Routledge. 
Varman, R. \& Vikas, R. M. (2007) Freedom and Consumption: Toward Conceptualizin SystemicConstraints for Subaltern Consumers in a Capitalist Society. Consumption, Markets and Culture, 10(2), pp. 117-131.

Wallis, V. (2010). Beyond "Green Capitalism." Monthly Review: An Independent Socialist Magazine, 61(9), pp. 32-48. 